\title{
Cuestiones éticas y legales del uso de pruebas rápidas de diagnóstico para VIH/SIDA domiciliarias
}

\author{
MARGOT VIDAL(1)
}

\section{RESUMEN}

La epidemia del VIH/SIDA se expande en forma alarmante por el mundo mundo, 9 de cada 10 personas que han adquirido el virus del VIH desconocen que están infectadas, por lo tanto siguen teniendo relaciones sexuales de riesgo y contagiando. El objetivo de este estudio es generar una discusión ética y legal sobre el uso de pruebas rápidas de VIH/SIDA de uso domiciliario en Latinoamérica.

Actualmente están por introducirse en Latinoamérica pruebas de diagnóstico rápido para VIH/SIDA de uso domiciliario, que podrían ser de gran utilidad en la lucha contra su expansión. Son más atractivas, debido a la rapidez de disponibilidad de los resultados y a que proveen mayor privacidad, sin embargo, su disponibilidad en las farmacias también conlleva riesgos por la falta de consejería pre y pos-test, y porque corren el riesgo de ser utilizadas sin el adecuado consentimiento.

La introducción de estas pruebas si bien implica una esperanza de detener la propagación de la infección, debido a que propicia la auto evaluación y con ello el conocimiento sobre su estado sexológico, también involucra consideraciones éticas y legales que nos deben llevar a reflexión. Esto para que no ocurra que en vez de hacer un bien, hagamos más daño, ya que es necesario preparar un escenario en el cual prime el respeto de los derechos de las personas para que introducir estas pruebas sea una herramienta eficaz para la lucha contra el VIH/SIDA.

Palabras clave: VIH/SIDA, bioética, derechos humanos, pruebas rápidas domiciliarias.

\section{ABSTRACT}

\section{ETHICAL AND LEGAL ASPECTS OF RAPID HIV/AIDS DIAGNOSIS HOME TESTING}

The HIV/AIDS epidemics is spreading worldwide alarmingly; 9 out of 10 people having acquired the virus ignore they are infected, and thus continue practicing unsafe sex and perpetuating contagion.

The purpose of this study is to elicit a discussion on the ethical and legal aspects of the use of rapid HIV/AIDS diagnosis home testing in Latin America.

Currently, rapid HIVIAIDS diagnosis home testing is soon to be implemented in Latin America, being of great use to impede the disease expansion. Such tests are more attractive, by virtue of their rapidity to provide results and the atmosphere of preserved privacy they generate, nevertheless,

(1) Centro Interdisciplinario de Estudios en Bioética, Universidad de Chile. Unidad de Bioética OPS-OMS. anzardo2004@yahoo.com. 
their availability in pharmacies constitutes a risk resulting from the lack of pre and post testing counseling, and because they are likely to be used without the proper consent. Although the implementation of such techniques provides the hope of stopping the spread of the infection, because it promotes self-assessment and thus the awareness of the self-sexologic status, it also entails ethical and legal considerations that should lead us to reflection. The latter might ensure that no harm results from the genuine intention to provide a benefit, since it is necessary to prepare a scenario in which human rights respect prevail, in such a manner that the introduction of these testings becomes an efficient tool against HIV/AIDS.

Keywords: HIV/AIDS, bioethics, human rights, rapid home testing.

\section{INTRODUCCIÓN}

Catorce mil personas adquieren el virus de VIH cada día en el mundo, 9 de cada 10 desconocen su diagnóstico. La epidemia para fines del 2004 habría cobrado 30 millones de vidas en el mundo, se estima que en la actualidad 40 millones de personas viven con VIH/SIDA, el $95 \%$ se encuentra en países en vías de desarrollo ${ }^{1}$.

Una de las principales estrategias para evitar que esta epidemia se siga extendiendo, es hacer un diagnóstico temprano de las personas infectadas, de manera tal que reciban tratamiento oportuno y se tienda a evitar la propagación de la adquisición del virus a través de relaciones sexuales de riesgo sin protección por desconocimiento de la serología. El Test Elisa es considerada la prueba estándar de diagnóstico porque tiene muy alta sensibilidad y especificidad (99,5 y 99,8 respectivamente) $)^{2-4}$.

Sin embargo su aplicación tiene algunas dificultades, que no se relacionan con la prueba directamente, como el riesgo de ser reconocido al acudir a los centros de salud donde se realizan, o las que se relacionan con la misma prueba, como que se requiere para su aplicación de un buen entrenamiento y un aparato especial para leer los resultados, los cuales están disponibles en 24 a 48 horas. Por esa razón, cuando una persona que se hace la prueba de Elisa debe regresar al otro día para recibir el resultado, permanece angustiada durante ese lapso y, en algunos casos, desiste de conocer su resultado. Prueba de esto es lo reportado por el Centro de Prevención y Control de Enfermedades Infecciosas de los EE.UU. "de 2,5 millones de personas a las que se realizó la prueba de descarte en 1995: $25 \%$ de las positivas y $33 \%$ de las negativas no recibieron sus resultados, calculando en 1998 un total de 697.495 personas que en el mundo podrían haber conocido sus resultados si se hubieran usado pruebas rápidas para $\mathrm{VIH}^{5,6}$.

En este aspecto es necesario también recordar que cada país tiene procedimientos para la entrega oficial del diagnóstico, y que un solo Elisa reactivo o no, no diagnostica o descarta por si solo la presencia o ausencia del virus y lo mismo ocurriría en el caso de pruebas rápidas de diagnóstico para VIH/SIDA.

En el caso de Chile, la Resolución Exenta 371, que regula el proceso de detección de VIH, indica que después de un primer Elisa reactivo o dudoso se debe realizar otro examen en duplicado, si, al menos, 2 de estos 3 exámenes resultan dudosos, débilmente reactivos o reactivos se envían al Instituto de Salud Pública (ISP), donde tras nuevas pruebas se entrega el diagnóstico: en el caso de resultar positivo se solicita una segunda muestra de sangre al paciente -prueba de identidad-, y sólo si ésta resulta positiva se confirma el diagnóstico. En Perú se requieren 2 Elisa para VIH reactivos y sólo en este caso se procede a su confirmación a través de un Western blot realizado a través del Instituto Nacional de Salud (INS). De tal manera que tanto los Elisa para VIH/SIDA como las pruebas rápidas de diagnóstico requieren confirmación a través de otros exámenes. La introducción de estas últimas involucraría, además, discusiones sobre la confiabilidad que proporcionarían, más si son realizadas en los domicilios por las personas interesadas en 
conocer su estado serológico. Podrían ser mal realizadas y peor aún, mal entendidas cuando se presenten resultados débilmente reactivos, dependiendo del laboratorio que las produce podría variar su habilidad para diagnosticar la infección por el VIH/SIDA en el periodo ventana.

En relación a este aspecto, es importante remarcar que normalmente las prueba de Elisa -en su mayoría exceptuando a los Elisa de 4ta generación-, sólo detectan la presencia de anticuerpos para $\mathrm{VIH}$, no así partículas virales (p24). Esto hace que el período de ventana para el diagnóstico sea no menor a ocho semanas desde el momento de la adquisición del virus, siendo el período de ventana de tres meses con cualquier Elisa de $3^{\mathrm{a}}$ generación (que son los que generalmente se utilizan en los centros de salud). En este caso el resultado sólo es válido si la persona no ha tenido conductas de riesgo durante los últimos tres meses, en el caso de las pruebas rápidas de diagnóstico para VIH/SIDA sucede lo mismo, ya que sólo detectan anticuerpos, por lo cual es de suma importancia que sea de conocimiento de los posibles usuarios de estas pruebas rápidas domiciliarias. La primera prueba rápida para VIH aprobada por FDA fue el Single Use Diagnostic System (SUDS) VIH-1, el cual mostró una sensibilidad del $99.9 \%$ y una especificidad $99.6 \%$ siendo comparable con el estándar del tipo Elisa7. E1 último aprobado por la FDA es el OraQuick Rapid HIV-1 Antibody Test, que tiene un 99.6\% de eficacia8. Actualmente existen en el mercado a nivel mundial más de 60 pruebas rápidas para $\mathrm{VIH}^{9}$, muchas de ellas con características similares al Elisa ${ }^{10-15}$.

Una prueba rápida para VIH es definida como una prueba de diagnóstico que revela la presencia o ausencia de anticuerpos para VIH en sólo 10 a 20 minutos, teniendo la ventaja de que la persona conozca el mismo día su resultado, reduciendo el tiempo de espera y eliminando el estrés ${ }^{16}$. A su vez, no requiere entrenamiento para su aplicación ni un lector especial para obtenerse los resultados. Esto hace que sea posible su realización no sólo en los centros de salud, por personal entrenado, sino que puede hacérsela uno mismo en la intimidad de su casa, eliminando así el temor a ser reconocido. Esto facilitaría, en teoría, que más personas se hicieran la prueba de descarte. Sin embargo como ya lo mencionamos podría darse el caso de que el resultado no fuera fácil de interpretar como el "débilmente positivo", porque dependerá de la agudeza visual y la subjetividad de quien lo lee, que podría estar afectada, incluso asustada por una probable infección por el virus, y deseosa de que el resultado fuera negativo. Todo esto es perjudicial, no sólo para la persona realmente infectada porque retrasaría su tratamiento, sino también para sus futuros contactos sexuales.

El motivo de la realización de este ensayo, es la pronta comercialización en las farmacias de las pruebas rápidas de VIH/SIDA de uso domiciliario, en países de América Latina, introducción que si bien implica una esperanza de detener la propagación de la infección, también involucra consideración éticas y legales que nos deben llevar a reflexión para que no ocurra que en vez de hacer un bien, hagamos mas daño.

\section{OBJETIVO}

En el presente trabajo analizaremos algunos derechos señalados en la segunda consulta internacional sobre VIH/SIDA y los derechos humanos, así como también los principios de bioética que están implicados en la realización y comercialización de pruebas rápidas de diagnóstico para VIH de uso domiciliario.

E1 VIH/SIDA, los derechos humanos y las consideraciones éticas que implica: "Varios años de experiencia en la lucha contra la epidemia VIH/SIDA han confirmado que la promoción y protección de los derechos humanos es un factor esencial para prevenir la transmisión del VIH y reducir los efectos del VIH/SIDA.

La promoción y protección de los derechos humanos es necesaria tanto para proteger la dignidad de las personas afectadas por el VIH/SIDA como para alcanzar los objetivos de salud pública consistentes en reducir la vulnerabilidad a la infección VIH, paliar los efectos negativos del VIH/SIDA en los afectados y dotar de medios a las personas y comunidades 
para responder a la epidemia"17.

Respetar los derechos de las personas, nos asegura un actuar ético, y viceversa ya que al respetarlos respetamos al mismo tiempo los principios fundamentales de Bioética: No maleficencia, justicia, beneficencia y autonomía, por lo tanto, el derecho y la ética se potencian uno al otro.

Entre los principales derechos humanos relacionados con el VIH/SIDA y la comercialización de pruebas rápidas de VIH de uso domiciliario consideraremos los siguientes:

\section{Derecho a la intimidad de la vida privada y el principio de No maleficencia.}

El artículo 7 del Pacto Internacional de Derechos Civiles y Políticos dispone que "nadie será objeto de injerencias arbitrarias o ilegales en su vida privada, su familia, su domicilio o su correspondencia, ni de ataques ilegales a su honra y reputación. Toda persona tiene derecho a la protección de la ley contra esas injerencias o esos ataques"17.

El derecho a la intimidad de la vida privada comprende obligaciones relativas a la intimidad física. En nuestra tema de discusión en particular en relación al VIH, el Estado tiene la obligación de no negar el derecho de las personas a conocer su situación respecto al VIH. Por consiguiente el acceso a la realización de toda prueba diagnóstica que se lo facilite, más aún si ésta le permita guardar su privacidad en mayor grado que con otras pruebas y disminuir el riesgo de ser identificado y discriminado, pero la realización de una prueba de diagnóstico hecha en casa, no asegura del todo la privacidad de la persona que compra la prueba en las farmacias, si es que no existe un compromiso de confidencialidad de aquellas personas que se lo venden. Es deber del Estado garantizar la privacidad de esas personas, lo que puede ser logrado a través del Derecho, dando una sanción a aquellos que violen esa privacidad, especialmente ahora con la pronta comercialización de las pruebas rápidas de diagnóstico de VIH caseras. Esto comprende la obligación de garantizar que se apliquen salvaguardias adecuadas para que no se realicen pruebas sin consentimiento fundado, que se proteja la confidencialidad, particularmente en el ámbito de la salud y el bienestar sociales, y que la información sobre la situación respecto del VIH no se revele a terceros sin el consentimiento de la persona.

El interés de la persona centrado en su intimidad es particularmente importante respecto del VIH/SIDA, por el estigma y la discriminación, que acarrean la pérdida de intimidad y confidencialidad si se revela su situación respecto del VIH.

Es importante, pues, que al dar acceso a estas pruebas rápidas de diagnóstico de $\mathrm{VIH}$, nos aseguremos de que, queriendo hacer un bien, siguiendo el principio de beneficencia, no hagamos mas daño, no cuidando que la realización de esa prueba sea totalmente confidencial, y violemos sin querer el principio de No maleficencia: "PRIMERO NO HACER DAÑO”.

\section{Derecho a disfrutar de los adelantos científicos y de sus aplicaciones y el principio de Beneficencia.}

El principio de Beneficencia, impone la obligación moral de actuar en beneficio de $\operatorname{otros}^{18}$. Los adelantos científicos y sus aplicaciones son importantes en este sentido y en relación con el VIH/SIDA dado los rápidos y constantes adelantos de los análisis, las terapéuticas y la elaboración de una vacuna cuyo principal objetivo es beneficiar a las personas afectadas o en riesgo de contraer el VIH/SIDA.

Por otro lado, si bien el mundo entero ha estado preocupado de que en todos los países las personas que viven con VIH tengan acceso al tratamiento antirretroviral y gracias al apoyo del Fondo Global de la lucha contra el SIDA, la Tuberculosis y la Malaria se está consiguiendo. ¿De qué valdrá que exista disponibilidad de tratamiento antirretroviral si aún muchas personas ignoran que están viviendo con el VIH? ¿Qué sentido tiene el avance de la ciencia si no puede la humanidad disfrutar de sus beneficios?

Tener acceso a estas nuevas pruebas diagnósticas es un derecho sustentado también en el principio de beneficencia. Es claro que 
éste proporcionaría mayores beneficios a las personas que las pruebas convencionales, ya que es una nueva herramienta diagnóstica con rápidos resultados, de fácil aplicación y ofrece mayor privacidad desde el momento en que se puede realizar en sus propios hogares, la cual estaría eliminado una de las principales razones por la que las personas no acuden a los centros de salud a realizarse la prueba: el temor a ser reconocido y discriminado. Sin embargo estos beneficios podrían no ser vistos si no se toman adecuadas medidas de control.

\section{El derecho de no discriminación y el principio de justicia.}

"La normativa internacional de derechos humanos garantiza el derecho a la igualdad ante la ley y a la no discriminación, sin distinción alguna de raza, color, sexo, idioma, religión, opinión política o de cualquier otra índole, origen nacional o social, posición económica, nacimiento o cualquier otra condición.

La discriminación por cualquiera de estos motivos no sólo es injusta en sí, sino que crea y mantiene condiciones que conducen a la vulnerabilidad social en la infección por VIH, en particular la falta de acceso a un entorno favorable que promueva el cambio de conductas y permita a las personas hacer frente al VIH/SIDA"17.

Una epidemia que apareció simultáneamente con la del VIH/SIDA, es la que se refiere a la discriminación. Esta última es más cruel, ya que muchas personas que viven con VIH o que están en riesgo de adquirirlo prefieren seguir ignorando su situación a ser señalados y discriminados por vecinos, amigos o lo que es peor por sus familiares al acudir a un Centro de Salud a realizarse la prueba de Elisa. El tener acceso a pruebas rápidas de diagnóstico de VIH en las casas, reduciría el riesgo de discriminación para aquellas personas que ignoran hasta ahora su condición con respecto al VIH por este temor.

El principio de justicia se refiere a que se le dé a cada ser humano lo que merece, lo que tiene derecho como persona, basado en normas que defiendan el sentido y el fin de la cooperación social ${ }^{18}$. Por lo tanto es de justicia que cualquier persona que desee conocer su estado de salud, pueda acceder a las pruebas diagnósticas sin temor a ser discriminada por ello, por lo tanto, es deber del Estado proporcionar las condiciones favorables para que se ejerza dicho derecho.

\section{El derecho a recibir información y difundirla y los principios de No maleficencia y de Autonomía.}

El artículo 19 del Pacto Internacional de Derechos Civiles y Políticos declara que: "Toda persona tiene derecho a la libertad de expresión; este derecho comprende la libertad de buscar, recibir y difundir informaciones e ideas de toda índole,..." Por tanto, este derecho comprende el derecho a buscar, recibir y difundir información relacionada con la prevención y atención médica del VIH/SIDA ${ }^{17}$.

Uno de los más grandes temores acerca de la introducción de las pruebas rápidas para VIH/SIDA domiciliarias, son las consecuencias negativas de la ausencia de consejería pre y postest, que si bien se realiza en la actualidad con la aplicación de Elisa para VIH en los centros de salud; y existe en la legislación de algunos países de Latino América (Chile y Perú) una ley que no permite la realización de un Elisa para VIH sin previa consejería. Dicha consejería podría no estar considerada para estas nuevas pruebas de diagnóstico ya que hasta hace poco la única prueba de descarte existente era el Elisa.

La importancia de la consejería radica en que ambas son indispensables, la realizada previamente para que la persona, si obtuviera un resultado negativo, no se vuelva a poner en riesgo de contraer la infección y la posterior al examen para evitar una reacción que podría llevar a que la persona se hiciera daño a si misma al no estar preparada para un resultado positivo. En un estudio realizado en Nueva York en que se evaluó a 207 mujeres $\mathrm{VIH}(+)$, el 27\% reportó un intento de suicidio desde su diagnóstico por $\mathrm{VIH}, 42 \%$ de ellas en el primer mes y $27 \%$ en la primera semana ${ }^{19}$.

Es importante en este sentido que las organizaciones de la sociedad civil vigilen que esta ley también se cumpla para la aplicación de las pruebas rápidas de diagnóstico para VIH.

Otro de los temores de la realización de las pruebas para VIH/SIDA domiciliarias, está en 
relación al consentimiento informado, la aplicación de las pruebas diagnósticas caseras imposibilita su existencia y al no haber un control por personal de salud familiarizado con obligaciones éticas y legales en la aplicación de estas pruebas, existe el riesgo de que algunas personas podrían ser forzadas a realizarse una prueba que debería ser totalmente voluntaria y no coaccionada y con total conocimiento de lo que este diagnóstico involucra.

En Bioética cuando hablamos del principio de autonomía, se refiere a la capacidad que tiene una persona a tomar decisiones, pero para que éstas sean consideradas realmente autónomas deben cumplir tres requisitos:

- Tener intencionalidad, lo cual quiere decir que esa decisión fue deseada por la persona.

- Tener pleno conocimiento del panorama sobre el cual toma las decisiones, es decir debe poseer toda la información disponible sobre el tema.

- No debe haber tomado la decisión bajo influencia de factores externos o terceras personas $^{20}$.

Por eso en relación a la introducción de pruebas rápidas para VIH/SIDA de uso domiciliario, es necesario reconocer que no basta con su disponibilidad en las farmacias, es necesario también, brindar toda la información necesaria al respecto. Es derecho de toda persona que al adquirir algo en este caso una de estas pruebas, reciba además información al respecto en nuestro caso sobre el VIH/SIDA, vías de adquisición, prevención, alternativas de tratamiento, además de información sobre la prueba rápida, cómo usarla, cómo leer los resultados y dónde acudir si resulta positiva, incluyendo un teléfono para llamar desde donde puede recibir consejería post-test.

Por tanto, es deber del Estado, salvaguardar este derecho de información, solicitando a las industrias proveedoras de estas pruebas, requisitos que aseguren se respete este derecho a estar informado y que, asimismo, no vean este servicio como una mera relación comercial, sino que actúen con responsabilidad en la epidemia, de manera tal que sean parte de la lucha contra el VIH/SIDA, que sea un acto de beneficio para las personas $\mathrm{y}$ no un acto de maleficencia.

\section{REFLEXIONES FINALES}

Retomando lo dicho en la $2^{\circ}$ consulta Internacional sobre el VIH/SIDA y los derechos humanos en Ginebra, en relación al uso de pruebas rápidas domiciliarias de VIH/SIDA:

En relación a la autorización o no de la introducción de pruebas rápidas para VIH/SIDA de uso domiciliario, los Estados no deberían adoptar una posición paternalista, semejante a la que adoptaban los médicos en relación a sus pacientes en la antigüedad, en que los veían como alguien falto de firmeza física y moral, por lo que el médico tomaba las decisiones por él, tal como un padre lo hace con su hijo con la finalidad de evitarle un sufrimiento. Hoy ese modelo no es aceptable porque no reconoce la autonomía de las personas, en su lugar se recomienda un modelo más bien deliberativo ${ }^{21}$ en el cual se actúe como un maestro o un guía moral, ofreciendo todas las alternativas posibles y recomendando las mejores opciones, pero es la persona y sólo ella la que finalmente toma la decisión, en el caso de las pruebas rápidas de diagnóstico para VIH/SIDA de uso domiciliario de adquirirlas, pero es el Estado el que debe velar para que estén dadas las mejores condiciones para la utilización de ellas.

Los Estados deberían garantizar la calidad y disponibilidad de las pruebas y asesoramiento sobre el VIH, la venta de pruebas rápidas domiciliarias para detectar el VIH, debería sujetarse a una reglamentación estricta de calidad y certeza. También debería tenerse en cuenta la falta de los consiguientes servicios de asesoramiento y el riesgo de utilización no autorizada, por ejemplo, a efectos de empleo o inmigración.

Para resguardar el derecho a privacidad que tienen las personas, se debería adoptar medidas que lo garanticen, como la creación de un organismo independiente encargado de reparar el quebrantamiento de la confidencialidad. Debería preverse que los colegios profesionales sancionen el quebrantamiento de la confidencialidad como falta profesional prevista en los códigos deontológicos, en el caso específico de la comercialización de las pruebas 
rápidas para VIH/SIDA de uso domiciliario, que estarán disponibles en su mayor parte en las farmacias se debería poner mayor énfasis en los profesionales químicos farmacéuticos responsables de estos establecimientos.

Los Estados deberían fomentar la difusión amplia y constante de programas creativos de educación, capacitación y comunicación diseñados explícitamente para convertir las actitudes de discriminación y estigmatización contra el VIH/SIDA en actitudes de comprensión y aceptación.

Los Estados deberían apoyar la formación o cursillos de derecho humanos y ética, en relación con el VIH.

Un instrumento importante para lograr el cambio social es la existencia de un entorno propicio y potenciador para realizar la prevención, atención y apoyo en relación con el VIH. Se puede conseguir en parte ese entorno mediante el cambio de las actitudes con una educación general y específica, la información pública y las campañas de educación sobre los derechos y la ética relacionados con el VIH.

Este ensayo pretendió orientar la respuesta a las interrogantes que están en discusión en cuanto a la introducción de pruebas rápidas de diagnóstico para VIH/SIDA domiciliarias, una orientación inspirada en la normativa internacional de derechos humanos, en los principios fundamentales de Bioética y en la convicción de que al proteger los derechos humanos de las personas significa proteger su salud, sus vidas y su felicidad en un mundo aquejado por el VIH/SIDA.

\section{REFERENCIAS}

1. OMS. Departamento de VIH/SIDA. Tratar a 3 Millones de personas para 2005: Cómo hacerlo realidad: La Estrategia de la OMS. [Archivo PDF] 2005 [Fecha de acceso 4 de Agosto del 2005].70p.Disponible en: http:// www.aidslaw.ca/maincontent/issues/testing/finalrep orts/tofc.htm

2. Diagnostic tests for HIV, Med Lett Drugs Ther 1997; (39): 81-83.

3. BENETUCCI J, et al. Métodos Aplicados al diagnóstico y seguimiento de la infección por el HIV-1 en los adultos. En: SIDA y enfermedades asociadas. Buenos Aires-Argentina: Carcos S.R.L, 2001; 53-96.
4. SAVILLE R, CONSTANTINE N, CLEGHORN F, et al. Fourth-Gneration Enzime-Linked Immunosorbent Assay for the simultaneous Detection of Human Immunodeficiency Virus Antigen and Antibody. Journal of Clinical Microbiology 2001; (39): 2518-2524.

5. CENTERS FOR DISEASE CONTROL AND PREVENTION. "Update: HIV Counseling and Testing Using Rapid Tests-United States 1995. MMWR 1998; (47): 211-215.

6. PAUL S, GRIMES-DENNIS J, BURR C AND DI FERNANDO T. Rapid Diagnostic Testing for HIV. Supplement to New Jersey Medicine 2003; 100(9): 11-17.

7. MACHADO A. Advantages of the rapid HIV-1 test in occupational accidents with potentially contamined material among health workers. Rev Int.Med trop S.Paulo 2001;43(4): 199-201

8. BRANSON BM, DEL RÍO C, LARRABEES, et al. Rapid fingerstick testing: a new era in HIV diagnostic. AIDS Clin Care 2003; (15): 19-23.

9. ELLIOT R JÛRGENS. Accuracy of Rapid Screening. [Documento PDF] En: Rapid HIV Screening at the point of care: Legal and ethical question. Canadian Strategy on HIV/AIDS, Montreal Canada, 2000: [Fecha de Acceso 5 de Abril del 2005].Disponible en: http://www.aidslaw.ca/maincontent/issues/testing/fi nalreports/tofc.htm

10. MALONE JD, SMITH ES. Comparativeevaluation of six rapid serological tests for HIV-1 antibody.J Acquir Immune De Syndr 1993; (6):115-19.

11. BLOOD SAFETY UNIT WHO/UNAIDS. HIV Test Kits. Comparative evaluation of the operational characteristics of commercially available assays to detect antibodies to HIV-1 and/or HIV-2 in human.[En Internet] [Fecha de Acceso 17 de diciembre del 2001] Disponible en: http://www.who.int/pht/ blood_safety/hivkits.html

12. BULTERYS M, JAMIESON D, O'SULLIVAN M, et al. Rapid HIV-1 Testing During labor A Multicenter Study. Jama 2004; 292(2) 219-223.

13. CARVALHO R, KRAHE C, FARINA G, et al. Teste Rapido para diagnostic da infeccao pelo HIV em pasrturients. RBGO 2004; 26(4): 325-328

14. BEHETS F, BISHAGARA K, DISASI A,et al. Diagnosis of HIV infection withinstrument-free assays as an alternative to the ELISA and western blot testing strategy: an evaluation in Central Africa. J Acquir Immune Def c Syndr 1992; (5): 878-82

15. KA N A N G A R, RA M A L INGA M S,PRADEEPKUMAR S, DAMODHARAN K, SRIDHARAN G. Hospital-based evaluation of two rapid human immunodeficiency virus antibody screening tests. J Clin Microbiol 2000; (38): 3445-7

16. CDC. Update HIV counseling and Testing Using Rapid Test-United States 1995. En: Morbidity and Mortality Weekly Report 1998; 47 (11) 
17. NACIONES UNIDAS. Comisión de derechos humanos. $2^{\circ}$ consulta Internacional sobre el VIH/SIDA y los derechos humanos. [En Internet] Ginebra, 1996. [Fecha de acceso 12 de Octubre del 2005].Disponible en: http:// www.unhchr.ch/ huridocda/huridoca.nsf/ (Symbol)/E.CN.4.1997.37.Sp?Opendocument

18. LOLAS F. Bioética: los principios fundamentales. En: El diálogo moral en las ciencias de la vida. Santiago, Buenos Aires, Montevideo: Ed.

Mediterráneo, 2003: 64-71.

19. COOPERMAN NA, SIMONI JM. Suicidal ideation and attempted suicide among women living with HIV/AIDS. J Behav Med. 2005; 28(2):149-56.

20. MANZINI R. Normas éticas para la investigación Clínica. [En Internet] 2002 [Fecha de acceso 28 de Junio del 2005]. Disponible en: http:// www.uchile.cl/ bioetica/doc/normas.htm
21. RODRÍGUEZ E. Relación médico-paciente y práctica médica. En: Diálogo y Cooperación en Salud. Diez años de bioética en la OPS. Santiago de Chile: Unidad de Bioética OPS, 2004; p.61-72.

\section{AGRADECIMIENTOS}

A todo el equipo de profesionales del Centro Interdisciplinario de Estudios en Bioética, Universidad de Chile, Unidad de Bioética: OPS-OMS, por su guía constante y apoyo. Al Fogarty Internacional, NIH-USA por brindarme el apoyo financiero para capacitarme en Bioética (Grant 5R25TW006056-04) y por consecuencia hacer posible la discusión de este ensayo.

Ud. puede comentar éste y otros artículos publicados en la Revista de Salud Pública, enviando un correo electrónico a revistasp@med.uchile.cl 